\title{
Phase angle is a better indicator of nutritional status than body mass index in patients on hemodialysis
}

\author{
Jorge F. Topete-Reyes, ${ }^{1}$ Carlos A. López-Lozano, ${ }^{1}$ Sandra L. López-Báez, ${ }^{1}$ Anel V. Barbarín-Vázquez, ${ }^{1}$ \\ Ma. L. Cervantes-Villalobos, ${ }^{1}$ Jesemil Navarro-Rodríguez, ${ }^{1}$ Renato Parra-Michel, ${ }^{1}$ \\ H. Leonardo Pazarín-Villaseñor, ${ }^{1}$ Daniela Meza-Guillén,, ${ }^{2}$ Margarita Torres-Tamayo, ${ }^{3}$ \\ Aída X. Medina-Urrutia ${ }^{3}$ and Juan G. Juárez-Rojas ${ }^{3 *}$ \\ ${ }^{1}$ Instituto Mexicano del Seguro Social, Hospital General Regional 46, Nephrology Department, Guadalajara, Jalisco, Mexico; ${ }^{2}$ Secretaría de Salud \\ de la Ciudad de México; ${ }^{3}$ Instituto Nacional de Cardiología "Ignacio Chávez", Department of Endocrinology, Ciudad de México, Mexico
}

\begin{abstract}
Introduction: Multi-frequency bio-impedance analysis (BIA) accurately evaluates body composition. Objective: To assess nutritional status and its relationship with body mass index (BMI) or with BIA-obtained phase angle in patients with end-stage renal disease (ESRD) on hemodialysis. Method: BMI, BIA and dialysis malnutrition score (DMS) were assessed in 99 patients on hemodialysis ( $43.6 \pm 17.2$ years of age, $58.8 \%$ males). Multivariate linear regression analysis was used to determine BMI and phase angle independent associations with DMS. Results: Malnutrition risk (DMS > 13) showed a gradual increase among patients with normal BMI and phase angle (44.4\%), low BMI (45.8\%), low phase angle (64.0\%), and in those with both parameters at abnormal ranges (68.0\%). The phase angle was the only variable that was independently associated with patient nutritional status (standardized coefficient beta $-0.372, p<0.001$ ), accounting for $13.8 \%$ of DMS variation. Conclusion: Phase angle is inversely and independently associated with malnutrition risk in patients with ESRD, which suggests that BIA-assessed body composition might be better than BMI in the clinical assessment of patients with ESRD.
\end{abstract}

KEY WORDS: Body mass index. Phase angle. Bio-impedance. Subjective global assessment. Nutritional status.

\section{Introduction}

Currently, $10 \%$ of the world population suffers from kidney conditions. ${ }^{1}$ Although there are controversies in defining end-stage renal disease (ESRD), this is an advanced stage that involves glomerular filtration < $15 \mathrm{~mL} /$ minute and is characterized by uremia and need for replacement therapy with peritoneal dialysis, hemodialysis (HD) or transplant. ${ }^{2}$ Numerous studies have reported that patients on HD have an elevated frequency of hospital admissions and poor quality of life. ${ }^{3,4}$ In these patients, problems are observed that are even more serious than those identified in patients with different types of cancer ${ }^{5}$ and one- and five-year overall mortality is higher than $20 \%$ and $60 \%$, respectively, which implies more than 10 times the rates observed in the general population. ${ }^{6}$

Epidemiological studies in patients treated with HD have described a paradoxical association between cardiovascular risk factors and mortality. This phenomenon, referred to as reverse epidemiology, highlights the finding that subjects with normal body mass index (BMI) have a worse survival prognosis in comparison with patients with overweight. ${ }^{8}$ Recent works suggests that this inverse relationship can be partially explained by physical fitness. ${ }^{9,10}$ In addition, muscle deconditioning has been recognized as an abnormal metabolic profile marker ${ }^{11}$ and has been found to be associated with mortality. ${ }^{12-14}$
Gac Med Mex. 2019;155:211-216

Contents available at PubMed www.gacetamedicademexico.com 
BMI is widely used in epidemiological studies to analyze body mass in relation with height. ${ }^{15-17}$ Although the method identifies subjects with low weight, normal weight, overweight and obesity, it does not allow differentiating fat mass (FM) and fat-free mass (FFM). ${ }^{18,19}$ On the other hand, in the clinical field, multi-frequency bio-impedance analysis (BIA) has been proposed as a simple, inexpensive and non-invasive method able to accurately estimate intracellular (ICBW), extracellular (ECBW) and total (TBW) body water distribution, in addition to $F M$ and $F F M, 18,20$ which indirectly reflect muscle status. ${ }^{21}$ BIA is based on the conductivity of low-intensity electric currents throughout the body, quantified as the electric potential differential, which is expressed as resistance (R) or reactance (Xc). $R$ is the opposition offered by the body to the flow of an alternating electric current and is inversely associated with the content of water and electrolytes in the tissues. Xc is related to the capacitance of cell membranes and, hence, it is dependent on cell composition, function and integrity. ${ }^{21,22}$ Based on these parameters, the phase angle (PA) is obtained, which has been proposed as a useful prognostic marker in clinical conditions such as ESRD, which is associated with changes in cell membrane integrity and fluid balance alteration. ${ }^{21-24}$

In patients treated with $\mathrm{HD}$, protein-calorie malnutrition and protein-energy wasting syndrome are frequent and favor FM and FFM loss, even in cases with adequate caloric intake. ${ }^{25,26}$ The anthropometric tools that assess body adiposity distribution do not allow adequately identifying the nutritional status of patients on HD. To the best of our knowledge, no works have been conducted analyzing the usefulness of BIA in comparison with BMI to assess the nutritional status of patients with ESRD. Therefore, the purpose of the present study was to investigate the relationship of $\mathrm{BMI}$ and BIA-obtained PA, with the risk of malnutrition being assessed with the Dialysis Malnutrition Score (DMS), which is a validated method to define the nutritional status in patients on $\mathrm{HD} .^{25}$

\section{Method}

Cross-sectional study that included patients older than 18 years with $\mathrm{ESRD}^{2}$ diagnosed by a glomerular filtration rate lower than $15 \mathrm{~mL} /$ minute $/ 1.73 \mathrm{~m}^{2}$ and on treatment with HD at the Nephrology Department of the 46 Regional General Hospital of the Mexican Institute of Social Security, in Guadalajara, Jalisco, Mexico. The patients had vascular access through central catheter or internal arteriovenous fistula. Treatment with HD went on for at least three months in all patients and different kidney damage etiologies were included.

Of 121 patients identified with $\mathrm{BMI}<30$ and without evidence of previous surgeries, liver damage, autoimmune diseases or malignant tumors, 18 were excluded for incomplete information, three for infection at the time of assessment and one for antibiotic consumption in the previous three months. The study was approved by the ethics and research committee of the 46 Regional General Hospital (R-2017-1306-28 and Cl 14039 165) and was carried out under the standards established in the Declaration of Helsinki of 2013, Fortaleza, Brazil update. ${ }^{27}$ All patients who participated signed an informed consent letter.

All participants underwent clinical evaluation after the hemodialysis session. Weight was obtained with a Tanita digital scale (BF-692w, IL, USA) with $150 \mathrm{~kg}$ capacity and $0.1-\mathrm{kg}$ weight increase. Height was measured with a Seca 214 stadiometer (Hamburg, Germany), with 207$\mathrm{cm}$ range and $1-\mathrm{mm}$ variations. BMI was calculated as weight $(\mathrm{kg}) / \mathrm{squared}$ height $\left(\mathrm{m}^{2}\right)$. Cutoff points for adequate (BMI from 23 to 29.9) or inadequate weight (BMI <23) were established according to criteria proposed by the International Society of Renal Nutrition and Metabolism for patients on $\mathrm{HD}$ and peritoneal dialysis. ${ }^{26}$

To know the nutritional status, the dialysis malnutrition score was used. ${ }^{25}$ This method includes seven items that analyze weight change, dietary intake, gastrointestinal symptoms, functional capacity, time on replacement therapy, presence of comorbidities and signs of modifications in muscle and fatty compartments. DMS values $\leq 13$ were considered indicators of adequate nutritional status and figures higher than this value were considered indicative of high risk for malnutrition, according to previously published data in patients with ESRD. ${ }^{25,28}$

Multi-frequency BIA was carried out with a QuadScan 4000 equipment (Isle of Man, British Isles), with frequencies ranging from 5 to $200 \mathrm{kHz}$. Since the participants attend for HD treatment thrice weekly, the intermediate day was selected to perform the BIA, which was carried out within the first 30 to 60 minutes after $\mathrm{HD}$, as it has been suggested. ${ }^{29}$ For the assessment, the patients remained in supine position at least five minutes and had fasted for four hours. The electrodes were placed based on the previously described protocol. . $^{30,31}$ The obtained data included ICBW, ECBW, TBW, $R$ and $X c$. Electric potential differential measurements ( $R$ and $X c$ ) obtained by BIA were standardized according to the subjects' height $(\mathrm{R} / \mathrm{H}$ and $\mathrm{Xc} / \mathrm{H})$. This correction allows to calculate $P A$ as $\operatorname{TAN}^{-1}=[\mathrm{Xc} / \mathrm{H}] /[\mathrm{R} / \mathrm{H}]$, 
Table 1. Characteristics of patients with end-stage renal disease on hemodialysis, stratified by normal $(\leq 13)$ or poor nutritional status (>13), considering the malnutrition score for patients on hemodialysis (DMS)

\begin{tabular}{|c|c|c|c|}
\hline & $\begin{array}{c}\text { DMS } \leq 13 \\
(n=43)\end{array}$ & $\begin{array}{c}\text { DMS }>13 \\
(n=56)\end{array}$ & $\mathbf{p}^{*}$ \\
\hline DMS (AU) & $10.6 \pm 1.9$ & $18.7 \pm 4.4$ & $<0.001$ \\
\hline Males (\%) & 70.0 & 51.9 & 0.080 \\
\hline Age (years) & $37.9 \pm 15.5$ & $47.9 \pm 18.0$ & 0.004 \\
\hline Body weight (kg) & $63.7 \pm 12.8$ & $56.7 \pm 10.9$ & 0.003 \\
\hline BMI $\left(\mathrm{kg} / \mathrm{m}^{2}\right)$ & $22.8 \pm 3.8$ & $22.3 \pm 3.8$ & 0.476 \\
\hline Fat mass $(\mathrm{kg})$ & $12.2 \pm 6.4$ & $15.0 \pm 6.4$ & 0.045 \\
\hline Fat-free mass (kg) & $51.4 \pm 11.0$ & $41.8 \pm 10.6$ & $<0.001$ \\
\hline Resistance $(\Omega)$ & $497 \pm 104$ & $555 \pm 110$ & 0.012 \\
\hline Reactance $(\Omega)$ & $45.7 \pm 14.8$ & $43.1 \pm 15.3$ & 0.409 \\
\hline Resistance/height $(\Omega)$ & $304 \pm 70$ & $353 \pm 77$ & 0.002 \\
\hline Reactance/height $(\Omega)$ & $28.0 \pm 9.3$ & $27.3 \pm 9.8$ & 0.771 \\
\hline Intracellular water (L) & $20.7 \pm 4.4$ & $17.5 \pm 4.2$ & 0.001 \\
\hline Extracellular water (L) & $17.2 \pm 2.9$ & $15.2 \pm 2.7$ & 0.002 \\
\hline Total body water $(\mathrm{L})$ & $39.3 \pm 7.7$ & $33.9 \pm 7.0$ & 0.001 \\
\hline Phase angle $\left(^{\circ}\right)$ & $5.2 \pm 1.0$ & $4.4 \pm 1.2$ & 0.002 \\
\hline
\end{tabular}

with $\pm 0.1^{\circ}$ variation. A PA of 5 to $7^{\circ}$ was considered normal and values $<5^{\circ}$ were defined as abnormal. ${ }^{32}$

Patients were stratified according to adequate (DMS $\leq 13$ ) or inadequate nutritional status (DMS > 13). Variables are expressed as means \pm standard deviation, number of subjects or percentage. Means and frequencies were compared with Student's t-test or the chi-square test, respectively. Pearson's simple correlation analysis was used to learn about the relationship of DMS with clinical variables, body composition and bioelectrical data of patients. Multiple linear regression analysis was carried out with DMS as a dependent variable and age, gender, BMI, PA, kidney damage etiology and vascular access as covariates. The analyses were carried out with the SPSS statistical program version 15.0. P-values $<0.05$ were considered statistically significant.

\section{Results}

The study population included 99 patients on treatment with hemodialysis ( $58.8 \%$ males), with an age of $43.6 \pm 17.2$ years and BMl of $22.3 \pm 3.7 \mathrm{~kg} / \mathrm{m}^{2}$. Time

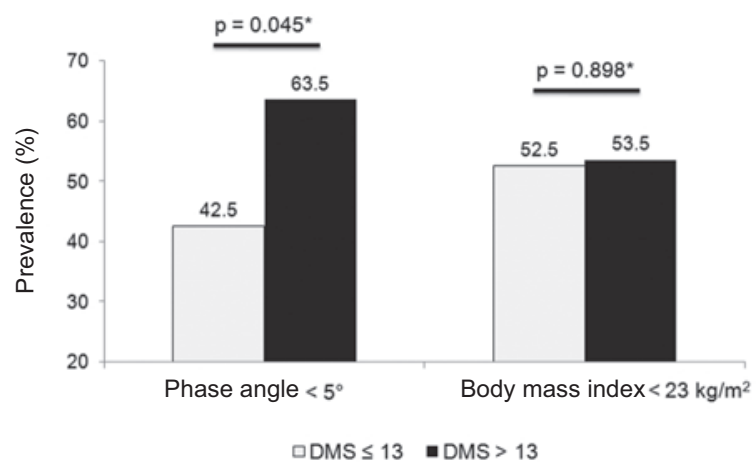

Figure 1. Prevalence of abnormal phase angle $\left(<5^{\circ}\right)$ and body mass index $\left(<23 \mathrm{~kg} / \mathrm{m}^{2}\right)$ in patients with end-stage renal disease on hemodialysis, stratified by normal (DMS $\leq 13)$ or poor nutritional status (DMS > 13). DMS = Dialysis Malnutrition Score. ${ }^{*}$ Chi-square.

on treatment with hemodialysis was 3 to 144 months (median of 42 and interquartile range of 21 to 68 ); in $59.6 \%$ of patients, vascular access was with central catheter and in $40.4 \%$ with internal arteriovenous fistula. Renal damage etiology was of unknown cause in most cases (58.6\%), followed by type 2 diabetes mellitus $(20.2 \%)$, hypertension $(6.1 \%)$, combination of diabetes and hypertension (6.1\%), glomerulopathies $(4.0 \%)$ and other causes (5.0\%). Body cell integrity analysis and nutritional status of participants showed that the average value of the former was below ( $\left.P A=4.77^{\circ} \pm 1.21^{\circ}\right)$ and the latter above (DMS $=15.2 \pm 5.4)$ values regarded as suitable.

Table 1 shows that, in comparison with patients who had an adequate nutritional status, those with DMS > 13 had significantly lower body weight, FFM and PA values. In addition, the group with high DMS was characterized for older age, higher FM, and resistance or resistance/height values, as well as less hydration (ICBW, ECBW and TBW). Finally, the results also indicated that, in comparison with subjects who had DMS $\leq 13$, those with malnutrition (DMS $>13$ ) had a higher prevalence of $\mathrm{PA}<5^{\circ}$, but similar low $\mathrm{BMI}(<23)$ (Figure 1).

Pearson's correlation analysis to know the relationship between body composition markers and patients' nutritional status showed that, unlike BMI and FM, PA and FFM significantly correlated with the DMS score (Figure 2). The multivariate analysis to find out DMS determining factors, including associated variables in the simple correlation and clinical determinants with biological plausibility, showed that PA was the only variable that was independently and significantly associated with patient nutritional status (standardized beta coefficient: $-0.372, p<0.001$ ). This association remained close and independent when hydration parameters were included in the analysis (standardized 

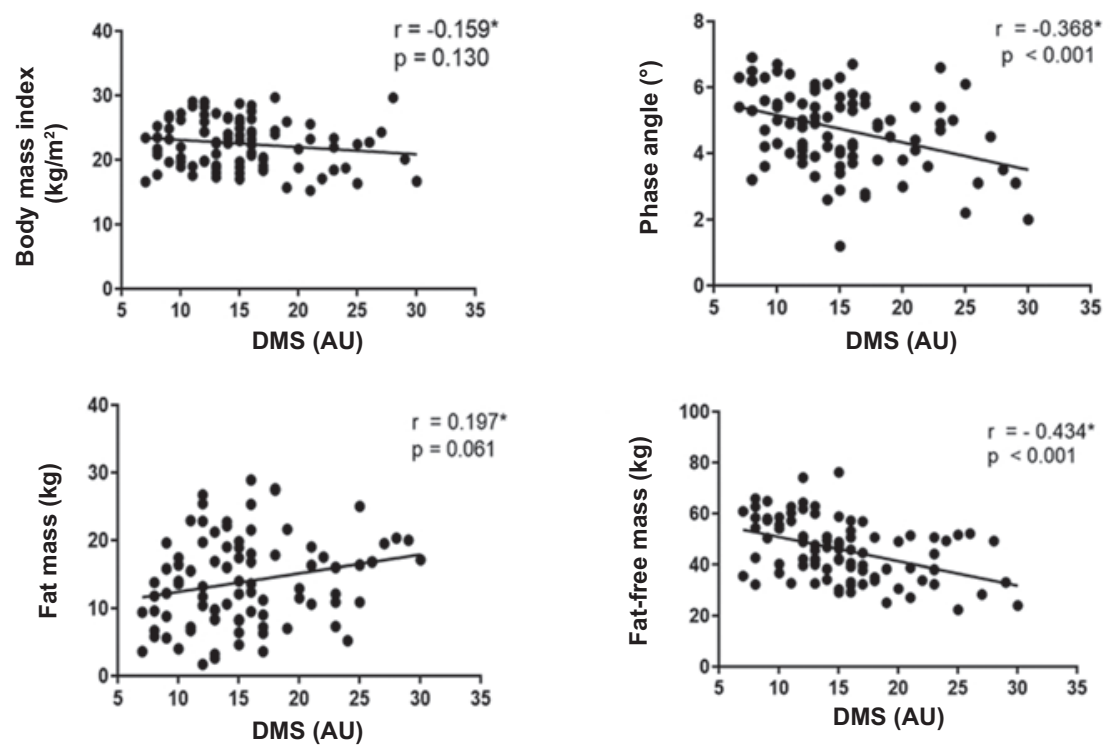

Figure 2. Correlation between body composition markers and nutritional status of patients with end-stage renal disease on hemodialysis. ${ }^{*}$ Pearson correlation coefficient. DMS = Dialysis Malnutrition Score, $A U=$ arbitrary units.

beta coefficient: $-0.391, p<0.001)$. The data indicate that PA accounts for up to $13.8 \%$ of DMS variation and that, for each PA unit increment, DMS decreases 1.651 units (Table 2).

\section{Discussion}

Multiple studies have described an inverse relationship between cardiovascular risk factors and mortality in patients with ESRD. ${ }^{6,7}$ Among the most important factors, BMI has shown a direct relationship with survival. ${ }^{8}$ However, this method for body composition assessment does not allow differentiating the proportion of fat mass and muscle mass, which might partially explain said relationship ${ }^{11-14} \mathrm{BIA}$ is a validated method for estimating the proportion of muscle, fluids and body fat, which also reflects physical fitness through the determination of PA. ${ }^{21}$ The present work highlights that PA is significantly associated with DMS, which has been shown to have an inverse relationship with survival in patients with ESRD. ${ }^{13,33}$ In addition, data of the present study show that, regardless of BMI and other clinical variables, PA accounted for almost $14 \%$ of DMS variation. This information suggests that the obesity paradox, described in patients with ESRD, could be due to a more favorable muscle mass distribution in subjects with high BMI.

ESRD is a major public health problem. In 2017, the International Society of Nephrology reported that nearly $10 \%$ of the world population suffers from chronic kidney disease. ${ }^{1}$ In Mexico, an annual increase of 7 to
Table 2. Association of age and body composition with the malnutrition score for patients with end-stage renal disease on hemodialysis

\begin{tabular}{|c|c|c|c|c|}
\hline & \multicolumn{2}{|c|}{ Pearson's coefficient } & \multicolumn{2}{|c|}{ Multiple linear regression* } \\
\hline & $\mathbf{r}$ & p & Beta coefficient & $\mathbf{R}^{2}(\%)$ \\
\hline Age (years) & 0.195 & 0.064 & - & - \\
\hline $\operatorname{BMI}\left(\mathrm{kg} / \mathrm{m}^{2}\right)$ & -0.159 & 0.130 & - & - \\
\hline $\mathrm{PA}\left({ }^{\circ}\right)$ & -0.368 & $<0.001$ & -1.651 & 13.8 \\
\hline $\mathrm{Xc}(\Omega)$ & -0.105 & 0.321 & - & - \\
\hline $\mathrm{R}(\Omega)$ & 0.334 & 0.001 & - & - \\
\hline $\mathrm{Xc} / \mathrm{H}(\Omega)$ & -0.056 & 0.599 & - & - \\
\hline $\mathrm{R} / \mathrm{H}(\Omega)$ & 0.374 & $<0.001$ & - & - \\
\hline ICBW (L) & -0.386 & $<0.001$ & - & - \\
\hline ECBW (L) & -0.363 & $<0.001$ & - & - \\
\hline TBW & -0.382 & $<0.001$ & - & - \\
\hline \multicolumn{5}{|c|}{$\begin{array}{l}\text { *The model includes age, gender, BMI, type of vascular access, kidney } \\
\text { disease etiology and phase angle as covariates. } B M I=\text { body mass index, } \\
P A=\text { phase angle; } X C=\text { reactance, } R=\text { resistance, } X / H=\text { reactance/ } \\
\text { height, } R / H=\text { resistance/height, ICBW }=\text { intracellular body water, } \\
\text { ECBW = extracellular body water, TBW=total body water. }\end{array}$} \\
\hline \multicolumn{5}{|c|}{$\begin{array}{l}10 \% \text { has been described in the number of patients } \\
\text { with ESRD and, specifically in Jalisco, in } 2013 \text {, a prev- } \\
\text { alence of } 1,654 \text { cases per million population was } \\
\text { found, which represents an increase of } 122 \% \text { in the } \\
\text { incidence of ESRD between } 2000 \text { and } 2013 .{ }^{34,35} \text { This } \\
\text { places Mexico in the highest places in the world. Dia- } \\
\text { betes has been reported to be the leading cause of } \\
\text { ESRD in the planet (> } 50 \% \text { ); however, the data of the }\end{array}$} \\
\hline
\end{tabular}


present work indicate that, in the study sample, $58.6 \%$ of cases were originated by undetermined causes, $32.4 \%$ by diabetes or hypertension and $9 \%$ by other causes. These differences might be explained by factors such as age, gender, ethnic group and other environmental factors that determine the kidney function. ${ }^{35}$ There is limited information on the probable causes of ESRD in Mexico and, as the data of the present work, previously reported information comes from Jalisco, a region located in the west of the country. ${ }^{35}$ Therefore, further information is required to adequately describe the characteristics of the Mexican population with ESRD.

In addition to being common, malnutrition in patients with ESRD on HD is associated with poor quality of life and higher morbidity and mortality. ${ }^{3,4,26}$ Among the main factors associated with mortality prognosis in this population, BMI has generated conflicting data. ${ }^{8-10}$ The results of this work show that the nutritional status of participants, assessed with the DMS, which reflects protein-energy depletion, was not statistically different when subjects were stratified by $\mathrm{BMI}(\mathrm{BMI}<23,15.9$ \pm 5.8 versus $B M I 23-29.9,14.4 \pm 4.7, p=0.181)$. On the other hand, when subjects with PA values regarded as normal $\left(5-7^{\circ}\right)$ and subjects with low PA $\left(<5^{\circ}\right)$ were compared, the latter had a higher degree of malnutrition (13.6 \pm 4.8 versus $16.5 \pm 5.5, p=0.009)$. In an additional analysis, more than half $(56.6 \%)$ the study patients were found to be at high risk of malnutrition (DMS $>13$ ) and this prevalence gradually increased when patients were stratified by normal BMI and PA (44.4\%), low BMI (45.8\%), low PA (64.0\%) and in those with both abnormal parameters $(68.0 \%)$. Although BMI has been employed to assess protein-energy depletion, this is a parameter that is highly influenced by fat mass or by hydration status, which are often found to be altered in patients with ESRD. ${ }^{26}$ The use of complementary tools such as PA assessed by BIA appears to be a more suitable alternative in the assessment of patients with ESRD, in whom metabolic damage progression and severe protein-energy depletion is accelerated and possibly masked by a clinical profile that includes hydration status, dialytic and pharmacological treatment and lifestyle.

Although the obesity paradox suggests that adiposity is inversely associated with mortality in patients with $\mathrm{ESRD},{ }^{8}$ this relationship is based on BMI, which is unable to differentiate body composition (FFM and FM). ${ }^{14,36}$ The International Society of Renal Nutrition and Metabolism has established that a BMI $<23 \mathrm{~kg} / \mathrm{m}^{2}$ might be a protein-energy depletion marker in patients with ESRD; however, the same panel recognizes that this cutoff point might require additional adjustments. ${ }^{26}$ Recent studies have proposed the use of BIA as a useful tool in the determination of body water, fat and muscle composition. ${ }^{37,38}$ With BIA, height-adjusted body resistance and reactance $(\mathrm{R} / \mathrm{H}$ and $\mathrm{Xc} / \mathrm{H})$ can be known, which allows to calculate the PA, which is associated with the nutritional status and mortality of patients with ESRD. ${ }^{33}$ This work's analysis shows that, unlike BMI, PA did correlate with DMS, which has been validated as a nutritional status marker in patients with ESRD. ${ }^{25}$

The most relevant finding of the present study indicates that PA was the only factor that was independently associated with DMS, accounting for up to $14 \%$ of its variation. It should be noted that this association was also independent of hydration status, which in patients with ESRD is frequently found to be elevated and is underestimated by BMI. ${ }^{18,37}$ Consistent with these results, previous data suggest that the protein-energy depletion observed in patients with kidney disease gradually increases during treatment with $\mathrm{HD},{ }^{26}$ a situation that has an important impact on body composition (body fluids, fat mass and fat-free mass) and might explain, at least in part, our results.

Among the most important strengths of the present study, the number of included subjects stands out, which allowed the analysis of all four groups in similar conditions, and the body composition determination that was performed after the HD session, which enabled obtaining more accurate body composition data. ${ }^{39}$ However, the present work has some limitations as well:

- Due to the cross-sectional design of the study, the data do not allow identifying the causality of the relationship of PA with patient nutritional status.

- Although DMS does not include an assessment of biochemical parameters such as transferrin and albumin, it is a used and validated method to know the nutritional status of the patient with $\mathrm{ESRD}^{25,28}$ that has shown similar results to those reported using the inflammation and malnutrition score ${ }^{6}$ or subjective global assessment, ${ }^{40}$ which are tools recommended by the International Society of Renal Nutrition and Metabolism that do require biochemical data.

- The lack of data regarding lifestyle makes it impossible to rule out the effect of diet and physical activity in the relationship that was found. 


\section{Conclusions}

PA was inversely and independently associated with malnutrition risk in patients with ESRD. This result suggests that BIA-assessed body composition could be important in the clinical assessment of patients with ESRD and possibly explain the inverse relationship of obesity with mortality; however, these results should be confirmed by follow-up studies in which mortality is included as the ultimate point of analysis.

\section{Acknowledgments}

The authors thank the participation of Itziri P. Mendoza Preciado, Miriam G. Nuño-Radillo and Anabel Salazar, for their support in data collection. We would also like to express our gratitude for the participation of the patients included in the study.

\section{References}

1. Bello AK, Levin A, Tonelli M, Okpechi IG, Feehally J, Harris D, et al. Global Kidney Health Atlas: a report by the International Society of Nephrology on the current state of organization and structures for kidney care across the globe. Bélgica: International Society of Nephrology; 2017.

2. Agarwal R. Defining end-stage renal disease in clinical trials: a framework for adjudication. Nephrol Dial Transplant. 2016;31:864-867.

3. Su CT, Yabes J, Pike F, Weiner DE, Beddhu S, Burrowes JD, et al. Changes in anthropometry and mortality in maintenance hemodialysis patients in the HEMO study. Am J Kidney Dis. 2013:62:1141-1150.

4. den Hoedt CH, Bots ML, Grooteman MPC, van der Weerd NC, Penne EL, Mazairac AHA, et al. Clinical predictors of decline in nutritional parameters over time in ESRD. Clin J Am Soc Nephrol, 2014:9:318-325.

5. Collins AJ, Foley RN, Chavers B, Gilbertson D, Herzog C, Ishani A et al. US renal data system 2013 annual data report. Am J Kidney Dis. 2014;63:A7.

6. Kalantar-Zadeh K, Block G, Humphreys MH, Kopple JD. Reverse epidemiology of cardiovascular risk factors in maintenance dialysis patients. Kidney Int. 2003;63:793-808

7. Kopple JD. The phenomenon of altered risk factor patterns or reverse epidemiology in persons with advanced chronic kidney failure. Am J Clin Nutr. 2005;81:1257-1266.

8. Kalantar-Zadeh K, Kopple JD, Kilpatrick RD, McAllister CJ, Shinaberger CS, Gjertson DW, et al. Association of morbid obesity and weight change over time with cardiovascular survival in hemodialysis population. Am J Kidney Dis. 2005;46:489-500.

9. Kalantar-Zadeh K, Kopple JD. Obesity paradox in patients on maintenance dialysis. Contrib Nephrol. 2006;151:57-69.

10. Lavie CJ, De-Schutter A, Parto P, Jahangir E, Kokkinos P, Ortega FB, et al. Obesity and prevalence of cardiovascular diseases and prognosis: the obesity paradox updated. Prog Cardiovasc Dis. 2016;58:537-547.

11. Ortega FB, Ruíz JR, Castillo MJ, Sjöström M. Physical fitness in childhood and adolescence: a powerful marker of health. Int J Obes (Lond). 2008:32:1-11.

12. Castellano S, Palomares I, MoissI U, Chamney P, Carretero D, Crespo A, et al. Identificar situaciones de riesgo para los pacientes en hemodiálisis mediante la adecuada valoración de su composición corporal. Nefrología. 2016 (3);36:268-274.

13. Prasad N, Sinha A, Gupta A, Bhadauria D, Manjunath R, Kaul A, et al. Validity of nutrition risk index as a malnutrition screening tool compared with subjective global assessment in end-stage renal disease patients on peritoneal dialysis. Indian J Nephrol. 2016;26:27-32.

14. Steene-Johannessen J, Anderssen SA, Kolle E, Andersen LB. Low muscle fitness is associated with metabolic risk in youth. Med Sci Sports Exerc. 2009;41:1361-1367.

15. Ng TP, Jin A, Chow KY, Feng L, Nyunt MSZ, Yap KB. Age-dependent relationships between body mass index and mortality: Singapore longitudinal ageing study. PLoS One. 2017;12:e0180818.
16. Berrington-De-González A, Hartge P, Cerhan JR, Flint AJ, Hannan L, Maclnnis RJ, et al. Body-mass index and mortality among 1.46 million white adults. N Engl J Med. 2010;363:2211-2219.

17. Whitlock G, Lewington S, Sherliker P, Clarke R, Emberson J, Halsey J, et al. Body-mass index and cause-specific mortality in 900000 adults: collaborative analyses of 57 prospective studies. Lancet. 2009; 373:1083-1096.

18. Garagarza C, João-Matias $P$, Sousa-Guerreiro C, Amaral T, Aires I, Ferreira $\mathrm{C}$, et al. Nutritional status and overhydration: can bioimpedance spectroscopy be useful in haemodialysis patients? Nefrologia. 2013; 33:667-674.

19. Park J, Ahmadi SF, Streja E, Molnar MZ, Flegal Katherine M, Guillen D, et al. Obesity paradox in end-stage kidney disease patients. Prog Cardiovasc Dis. 2014;56:415-425.

20. Earthman C, Traughber D, Dobratz J, Howell W. Bioimpedance spectroscopy for clinical assessment of fluid distribution and body cell mass. Nutr Clin Pract. 2007;22:389-405.

21. Rodríguez-Rodríguez F, Cristi-Montero C, Gónzalez-Ruíz K, Correa-autista JE, Ramírez-Vélez R. Bioelectrical impedance vector analysis and muscular fitness in healthy men. nutrients. 2016;8:407.

22. Di-Gioia MC, Gallar P, Rodríguez I, Laso N, Callejas R, Ortega O, et al. Changes in body composition parameters in patients on haemodialysis and peritoneal dialysis. Nefrologia. 2012;32:108-113.

23. Beberashvili I, Sinuani I, Azar A, Yasur H, Feldman L, Efrati S, et al. Nutritional and inflammatory status of hemodialysis patients in relation to their body mass index. J Ren Nutr. 2009;19:238-247.

24. Matthie JR. Bioimpedance measurements of human body composition: critical analysis and outlook. Expert Rev Med Devices. 2008;5:239-261.

25. Kalantar-Zadeh K, Kleiner M, Dunne $\mathrm{F}$ Lee GH, Luft FC. A modified quantitative subjetive global assessment of nutrition for dialysis patients. Nephrol Dial Transpl. 1999;14:1732-1738.

26. Fouque D, Kalantar-Zadeh K, Kopple J, Cano N, Chauveau P, Cuppari L, et al. A proposed nomenclature and diagnostic criteria for protein-energy wasting in acute and chronic kidney disease. Kidney Int. 2008;73:391-398.

27. World Medical Association. Declaration of Helsinki: ethical principles for medical research involving human subjects. JAMA. 2013:310:21921-2194.

28. As'habi A, Tabibi $H$, Nozary-Heshmati B, Mahdavi-Mazdeh M, Hedayati M. Comparison of various scoring methods for the diagnosis of protein-energy wasting in hemodialysis patients. Int Urol Nephrol. 2014:46:999-1004

29. Di-Iorio BR, Scalfi L, Terracciano V, Bellizzi V. A systematic evaluation of bioelectrical impedance measurement after hemodialysis session. Kidney Int. 2004;65:2435-2440.

30. Piccoli A, Rossi B, Pillon L, Bucciante G. A new method for monitoring body fluid variation by bioimpedance analysis: the RXc graph. Kidney Int. 1994:46:534-539.

31. Lukaski HC, Johnson PE, Bolonchuk WW, Lykken GI. Assessment of fat-free mass using bioelectrical impedance measurements of the human body. Am J Clin Nutr. 1985;41:810-817.

32. Bosy-Westphal A, Danielzik S, Dörhöfer R-P, Later W, Wiese S, Muller MJ. Phase angle from bioelectrical impedance analysis: population reference values by age, sex, and body mass index. JPEN J Parenter Enteral Nutr. 2006:30:309-316.

33. Segall L, Moscalu M, Hogas S, Mititiuc I, Nistor I, Veisa G, et al. Protein-energy wasting, as well as overweight and obesity, is a long-term risk factor for mortality in chronic hemodialysis patients. Int Urol Nephrol. 2014:46:615-621.

34. Cueto-Manzano AM, Cortés-Sanabria L, Martínez-Ramírez HR. Role of the primary care physician in diagnosis and treatment of early renal damage. Ethn Dis. 2009:19:S1-S68.

35. Saran R, Li Y, Robinson B, Abbott KC, Agodoa LY, Ayanian J, et al. US renal data system 2015 annual data report: epidemiology of kidney disease in the United States. Am J Kidney Dis. 2016:67:S1-S305.

36. Obi Y, Qader H, Kovesdy CP, Kalantar-Zadeh K. Lastest consensus and update on protein energy-wasting in chronic kidney disease. Curr Opin Clin Nutr Metab Care. 2015;18:254-262.

37. Kim YJ, Jeon HJ, Kim YH, Jeon J, Ham YR, Chung S, et al. Overhydration measured by bioimpedance analysis and the survival of patients on maintenance hemodialysis: a single-center study. Kidney Res Clin Pract. 2015;34:212-218

38. Atilano-Carsi X, Miguel JL, Ara JM, Villanueva RS, García G, Gutiérrez S. Vectores de impedancia bioeléctrica como herramienta para la determinación y ajuste del peso seco en pacientes sometidos a hemodiálisis. Nutr Hosp. 2015:31:2220-2229.

39. Espinosa-Cuevas MA, Rodríguez-Navarrete G, Villeda-Martínez ME, Atilano-Carsi X, Miranda-Alatriste P, Tostado-Gutiérrez T, et al. Body fluid volume and nutritional status in hemodialysis: vector bioelectric impedance analysis. Clin Nephrol. 2010;73:300-308.

40. Steiber A, Leon JB, Secker D, McCarthy M, McCann L, Serra M, et al. Multicenter study of the validity and reliability of subjective global assessment in the hemodialysis population. J Ren Nutr. 2007;17:336-342. 